Wien klin Mag 2021 · 24:85

https://doi.org/10.1007/s00740-021-00400-5

Angenommen: 3. Mai 2021

(c) Springer-Verlag GmbH Austria, ein Teil von Springer Nature 2021
Verena Kienast

SpringerMedizin, Wien, Österreich

\section{Joseph Beuys: Gesamtkunstwerk mit Strahlkraft}

\author{
Aufforderung zum kreativen und \\ empathischen Denken und Handeln
}

Es kommt auf die Kreativität an. So kann jeder Mensch ein Künstler sein - und ist es, dem prägnanten und prägenden gesellschaftlichen und künstlerischen Querdenker Joseph Beuys zufolge, auch. Heuer hätte der vielseitige und eigenwillige Kreative seinen 100. Geburtstag gefeiert und er hat mit seinen Impulsen in seiner Zeit nicht nur viel $\mathrm{Zu}$ - wie auch Widerspruch erlebt, sondern damit Denk- und Aktionsräume geöffnet, die wir heute großteils als selbstverständlich hinnehmen.

\section{Medial gut in Szene gesetzt}

Zur Breitenwirkung hat nicht zuletzt beigetragen, dass er seine Aktionen sowohl im direkten Kontakt mit seinen Mitmenschen als auch medial ziemlich wirksam in Szene gesetzt hat - und das ist auf jeden Fall rückblickend gut so. Denn Beuys schaute in seinem Tun immer über den Tellerrand. Er war sehr interessiert an den Naturwissenschaften und baute deren Erkenntnisse und Phänomene immer wieder in seine Installationen und Aktionen ein, er engagierte sich für den Umwelt- und Tierschutz in einer Zeit, als das Wirtschaftswachstum in der Nachkriegszeit den dominierenden Stellenwert hatte, und er vertrat ein gesamtheitliches Weltdenken, in dem Kunst - im weitesten Sinne - auch dazu beitragen kann, Kriege zu verhindern.

Sein Manifest „Aufruf zur Alternative" beschäftigt sich mit der Krisensituation der Welt Ende der 70er-Jahre und schlägt neue Modelle für Arbeit, Produktion und das Finanzsystem vor. Mit seiner
Aktion 7000 Eichen auf der documenta 7 im Jahr 1982 in Kassel veränderte er das Stadtbild nachhaltig. Unter dem Titel „Stadtverwaldung statt Stadtverwaltung" wurden da bis zum Jahr 1987 die insgesamt 7000 Eichen an unterschiedlichen Stellen der mitteldeutschen, kulturaffinen Stadt gepflanzt. Seine eigene mythologische Geschichte vom Flugzeugabsturz auf der Krim im 2. Weltkrieg und seine Rettung durch Tataren, die ihn mit Filz und Fett „heilten“, erhielt in seinem Werk einen durchgängigen Bezugspunkt. Die Geschichte ist auf jeden Fall gut erzählt und auch hier zeigt sich die Fähigkeit Beuys', die Symbolkraft von Ereignissen in einen größeren Zusammenhang zu stellen: $\mathrm{Ob}$ es darum ging „dem toten Hasen die Kunst zu erklären“, in einem Galerieraum in New York City drei Tage lang mit einem Koyoten zu verbringen und sich bei dieser eigenwilligen Kapitalismuskritik beobachten zu lassen, oder ob er 1977 bei der documenta 6 umgeben von der "Honigpumpe am Arbeitsplatz“ an 100 Tagen mit dem Publikum diskutierte. Man sollte darüber nachdenken und weiterdenken.

\section{Das Werk lebt vom Prozess}

Die Darstellung des Werks von Joseph Beuys, wie sie heuer anlässlich seines 100. Geburtstags vielerorts in Ausstellungen versucht wird, ist etwas schwierig, lebte es doch vor allem in der Aktion oft auch in der Interaktion, in der Diskussion und in der Performance. Seine Überlegungen allerdings lassen sich in Schriften und in der Umsetzung auch im durchaus reichen Filmmaterial nachvollziehen. Und schließlich folgt dies ganz gut dem Beuys'schen Anspruch: Das erste Produkt der menschlichen Kreativität ist der Gedanke. Dann aber geht es darum, Handlungen folgen $\mathrm{zu}$ lassen. $\mathrm{Zu}$ diesen Handlungen, die letztlich zu Neuem und Besserem führen sollten, waren eben auch die Aktionen und Performances als Initialzündung gedacht.

Joseph Beuys als Gesamtkunstwerk mit Strahlkraft - kantig, empathisch und sehr humorvoll. Er kann auch oder gerade heute, mehr als 30 Jahre nach seinem Tod, immer wieder Impulse geben für das eigene Denken und Handeln meint

Ihre<smiles>C=CC1CCC1CCC</smiles>

\section{Korrespondenzadresse}

\section{Verena Kienast}

SpringerMedizin

Wien, Österreich

Verena.kienast@springer.at

Interessenkonflikt. V. Kienast gibt an, dass kein Interessenkonflikt besteht.

Hinweis des Verlags. Der Verlag bleibt in Hinblick auf geografische Zuordnungen und Gebietsbezeichnungen in veröffentlichten Karten und Institutsadressen neutral. 